\title{
A REVIEW OF MODELS FOR THE ATMOSPHERIC DISPERSION OF HEAVY GASES. PART II. MODEL QUALITY EVALUATION*
}

\author{
PRZEGLACD MODELI DYSPERSJI W ATMOSFERZE \\ GAZÓW CIĘŻSZYCH OD POWIETRZA. \\ CZĘŚĆ II. OCENA JAKOŚCI MODELI
}

\begin{abstract}
This is the second paper of a two part review. In its first part mathematical models for atmospheric dispersion of heavy gases are classified and the distinguished groups of models are characterised. In this part procedures for the model quality evaluation are described and the main results of model evaluation exercises and databases with experimental data related to the subject are summarised. The quality of a model is clearly of great importance since the decisions concerning the safety of people, environment are based on model calculations. Attention is focused on activities carried out in the European Union countries and in the USA. These include the work of the groups of researchers called MEG, HGDEG, projects known under the names REDIPHEM, SMEDIS, DATABASE and the model evaluation exercise carried out by the Sigma Research Corporation.
\end{abstract}

Keywords: model quality evaluation, mathematical model, heavy gases, atmospheric dispersion

\section{Introduction}

This is the second article of the two part review concerning the mathematical models for atmospheric dispersion of heavy gases. Interest in the modelling of heavy gas dispersion goes back to the 1970s. The four decades of investigations have resulted in the development of a great number of heavy gas dispersion models of different complexity and different approaches to the description of physical and chemical processes. A classification of heavy gas dispersion models proposed was in the first article of this review [1], it can be treated as the extension of the classification proposed by the MEG (Major Evaluation Group) [2, 3]. It takes also from other reviews [4-10]. Four main groups of models are given the following names: simple/empirical models, intermediate/integral and shallow layer models, advanced/Lagrangian particle trajectory and Lagrangian puff models, sophisticated/CFD (Computer Fluid Dynamics) models. In the group of integral models four subgroups are

\footnotetext{
${ }^{1}$ Faculty of Environmental Engineering, Warsaw University of Technology, ul. Nowowiejska 20,

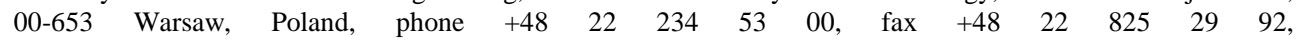
email: Maria. Markiewicz@is.pw.edu.pl

** Part I: Markiewicz MT. ECE S. 2012;19(3):297-314. DOI: 10.2478/v10216-011-0022-y.
} 
distinguished: box models, steady state plume models, generalised steady state plume models and one dimensional integral plume models. The group of CFD models includes three subgroups of models: RANS (Reynolds Averaged Navier Stocks equations) models, LES (Large Eddy Simulation) models and DNS (Direct Numerical Simulation) models. The heavy gas dispersion models have different capabilities and limitations and these influence their application. The models of the first three main groups and the RANS models are valuable engineering tools or have a potential to become so. The other CFD models are research tools. The status of the engineering tool is reserved for the models used in routine calculations for risk assessment, emergency response planning, environmental impact assessments and efficient land use planning. The research tools are needed to investigate the dispersion process in more detail.

The quality of models has been always of big concern to regulatory bodies, industry and researchers. An examination of the model quality is called model evaluation. The model evaluation can increase confidence in the use of a model and allow to determine research priorities by objectively assessing gaps in knowledge. When the model quality is considered it has to be noted that propagation atmospheric models will always involve a certain degree of imprecision and none of them can be perfect. The reasons are not only errors in the input data, model physics, numerical representation but also the stochastic character of the atmosphere $[11,12]$.

In the paper procedures for the quality evaluation of heavy gas dispersion models are reviewed, the main results of model evaluation exercises and databases with laboratory and field experiments related to the subject are presented. The attention is focused on projects carried out in the European Union countries and in the USA. This research on the quality evaluation of heavy gas dispersion models is only the part of activities concerning the quality evaluation of meteorological and air pollution dispersion models [13-33]. It needs to be mentioned that a list of publications on the comparisons of heavy gas dispersion model results with measurements carried out by authors of models has been included in the first part of this paper. It avoids doubling the references. However some publications describing new modelling work are given here [34-45].

\section{Experience in quality evaluation of heavy gas dispersion models in the seventies and the eighties}

The quality of atmospheric dispersion models has always been an important issue. In the seventies and early eighties there was a limited experience in the model quality evaluation. This concerned also the evaluation of heavy gas dispersion models. At this period the quality model evaluation has been usually understood as comparison of model results with measurements. These comparisons were usually done by authors of models and typically concerned a single model. Only sometimes models were tested by other researchers than the model authors, or model predictions were compared with results from other models instead of measurements. A review of comparisons of model results with measurements has been given by Mercer [46]. In this article it is shown that there was little conformity in the choice of parameters to be compared. The used parameters included: the bulk concentration as a function of distance or time, peak concentration as a function of distance or time, concentration at a given distance or time and cloud radius or height as a function of distance or time, location of a cloud centre, leading edge or trailing edge, peak 
concentration as a function of time, maximum downwind extent of the lower flammability limit (LFL) or 0.5 LFL. In essentially all comparisons only subjective, qualitative statements were made on how well model predictions compared with the data. It was concluded that techniques to assist in the objective discrimination of models were required and the objective quantitative measures of model performance were needed. It was noted that in the realisation of these tasks the understanding of the physical basis of various types of models was of great value. Some of these aspects have been also addressed by Fay and Ranck [47] and Wheatley and Webber [48].

In the eighties there were also some studies in which results from several models were compared with experimental data from different laboratory or field trials. These exercises included the work of Woodward et al [49], Ermak et al [50, 51] and Havens et al [52]. Woodward et al [49] compared the predictions of integral models (Germeles and Drake, Eidsvik, HEGADAS) and CFD models (ZEPHYR, MARIAH) with the measurements from Dutch Freon, Matagordo Bay and Porton Down trials. They compared the concentration contours and concentration versus distance. The results of MARIAH, ZEPHYR, HEGADAS and Eidsvik models agreed acceptably with the measurements beyond 35 meters from the source. In addition the results from the first two models matched well the measurements close to the source. It was postulated to test the models using other experimental data. Ermak et al $[50,51]$ compared the predictions of the three models of varying complexity (a modified Gaussian plume model of Germeles and Drake, a shallow layer SLAB model and a CFD FEM3 model) with the measurements from Burro field experiments. They compared the maximum distance to LFL, the location and shape of the concentration contours. The comparison of the cloud structure between the FEM3 model and the experiments was generally quite good. The SLAB model also compared fairly well with the experiment especially in the prediction of the maximum distance to the LFL. The Germeles and Drake model compared rather poorly with the observed cloud. It was recommended to evaluate models performance over a broad range of atmospheric conditions. Havens et al [52] evaluated four CFD models (FEM3, MARIAH, SIGMET-N and ZEPHYR). The quantity compared was the concentration versus distance. They found the FEM3 and MARIAH models to be the most suitable for dense gas application.

A step forward in systematic statistical model evaluation was done by Ermak and Merry [53]. They developed a methodology for evaluating dense gas dispersion models which concerned statistical testing. Based on the analysis of the processes characteristic for heavy gas dispersion four plume parameters emerged for comparison: the maximum gas concentration as a function of downwind distance from the source, average ground level plume centreline gas concentration as a function of downwind distance, plume half width and plume height. The recommended comparison technique was based on developing for each of these parameters the ratios between the values predicted by the model and the values from the experiments. The ratios allowed comparison over a wide range of values from high concentrations where gravity spreading effects dominated down to tracing concentration levels where ambient atmospheric phenomena dominated the flow dispersion.

The progress in the quality evaluation procedures became possible at the end of the eighties. It was agreed among the modellers that the statistical evaluation was only one part of the evaluation of dispersion models and that the evaluation of scientific basis, solution techniques, model description was at least equally important in assessing the usefulness of a model [13-16]. This brought new initiatives just in the end of the eighties and the early 
nineties. They concerned the development of procedures for the quality evaluation of heavy gas dispersion models which were based on the understanding of the specific processes involved and organising the experiments in which a set of models was evaluated using data sets from different experiments.

\section{Experience in the quality evaluation of heavy gas dispersion models from the nineties up till now}

\section{Procedures for the model quality evaluation}

A framework for the development of procedures for the quality evaluation for heavy gas dispersion models has been provided by a document on the evaluation on technical models used for major accident hazard installations issued in 1991 [54]. In this study a need for the guidance to the quality of the technical models and implementation of measures for improving the quality of these models is clearly formulated. In addition the basis for the evaluation protocol of technical models is set up. It is argued that model quality evaluation methodology should cover the scientific model assessment, statistical evaluation (validation), code assessment (assurance or verification) and user oriented assessment. In the scientific evaluation the model algorithms, physics and assumptions are examined in detail. The statistical model evaluation is a comparison between the model results and experimental data from field or laboratory. The code assessment is a check of the correctness of the code. The user oriented assessment considers issues related to the user friendliness of a model such as the user's guide, user interface, error checking of the model inputs, diagnostics of model calculations, processing and display of model outputs. It is recommended that the model evaluation needs to be carried out in a non-arbitrary and structured way in order to ensure acceptance and usefulness. It is noted that the European Union is an appropriate body to play a role in managing activity in the area.

The first structured guidance on how the quality of different groups of technical models may be assessed was developed by the Major Evaluation Group (MEG) [2, 3]. This group was set up by the CEC in 1992 after a number of consultations between industry, regulators and scientists in Europe. The aim of the MEG was to provide assistance in the technical model evaluation and to give users of these models a valuable support. The results of the work were issued in 1994. In the generic MEG protocol for the evaluation of technical models the model evaluation procedure includes three main components $[2,3,55]$ :

(i) scientific assessment, which comprises: the comprehensive model description, assessment of the scientific content, limits of applicability, limitations and advantages of the model;

(ii) verification, which deals with the question that the model produces the results in accordance with the specification;

(iii) validation, which deals with the results and their relevance to the situation in question and covers: the database selection, model characteristics, parameter selection, uncertainty estimation, selection of validation parameters, applicability of code comparison exercise, applicability of benchmarking.

In the protocol it is stressed that each step of the model evaluation process needs to be documented. The MEG protocol is consistent with the recommendations from the study from 1991. It was tested applying to heavy gas dispersion models and other groups of technical models in an open exercise carried out on a limited example in small expert 
groups. The results of the exercise generally confirmed usefulness of the MEG protocol however during the evaluation process difficulties were encountered. The large effort needed in performing the evaluation properly and the importance of the selected set of data used in the validation was reported. In particular: the lack of complete model documentation, insufficient information on how to treat the more complex CFD models, problems with detailed comparisons for transient releases were found. It was demonstrated that the protocol of model evaluation needs updating and refinement. It was noticed that to achieve this more research and a stronger link to users in industry and regulatory bodies were needed.

The work on the quality evaluation of technical model was also carried out for the legal authorities of the Southern Region of Belgium [56]. The quality assurance guide for the evaluation of mathematical models used to calculate the consequences of major hazards was produced independently of the work carried out by MEG. The intention was to offer the community of end-users a structure for collecting information from modelers which would enable the user to judge the quality of environmental software. In this quality assurance guide five components are distinguished [56]:

(i) scientific quality assurance;

(ii) algorithmic quality assurance;

(iii) computerisation quality assurance;

(iv) man-machine interface quality assurance and

(v) model validation and analysis of sensitivity.

The questionnaire form is chosen for the quality assurance guide. A set of structured questions is formulated to evaluate specific aspect of a model. There are 9, 10, 22, 2, 9 structured questions for each component respectively. It can be seen that the quality assurance guide is consistent with the MEG protocol in that it includes three basic model evaluation components however there are differences in terminology, verification covers two steps and the user oriented evaluation is introduced. In addition it is more detailed. The quality assurance guide was tested in an exercise however at the time when the publication was issued the final results were not known.

In 1993 the MEG set up an expert group on heavy gas dispersion (the HGD Expert Group) to continue the work [57]. The main aim was to produce an evaluation protocol specific to heavy gas dispersion models. Other tasks of the group included: the preparation of a classified list of heavy gas dispersion models, identification of data sets and arranging an open exercise to test the protocol. The HGD Expert Group was particularly fortunate in that the CEC sponsored REDIPHEM project had been carrying out very similar activities and had managed to finish most of the tasks before the HGD Expert Group completed its tasks [58]. The REDIPHEM (REview and DIssemination of PHysical Effects Models) project founded by CEC started in 1993 and was jointly carried out by TNO (nederlandse organisatie voor Toegepast Natuurwetenschappelijk Onderzoek, in Netherlandish: Netherlands organisation for applied scientific research) and Riso Danish National Laboratory (Riso). The main aim was to test selected mathematical models developed under CEC funding against experimental data. The results of work were issued in technical reports in 1994 and 1995. The tasks included in the project were the following: the formulation of the evaluation protocol for heavy gas dispersion, construction of the database with the available experimental data on dispersion of toxic or flammable gases in the atmosphere and organising the evaluation exercise in which guidelines for statistical model evaluation 
can be formulated. The last two tasks are reported in the following sections. The evaluation protocol for heavy gas dispersion prepared by Bakkum (1994) was issued as a technical report [59]. The HGD Expert Group accepted the protocol on the evaluation of heavy gas dispersion models produced within the REDIPHEM project after making some relatively minor changes and issued it in 1996. The HGD evaluation protocol divides the evaluation procedure into the following six steps [57]:

(i) model description, which contains: the name, version number and release date origin, area of application, name and data of the originating organisation, source and costs of the model, model type, hardware requirements, software requirements, quality assurance, list of publications;

(ii) database description which covers: the data type, data ownership and accessibility, origin of the data, data quality assurance, appropriateness of the data set, features and parameters covered by the data set;

(iii) scientific assessment which comprises: the comprehensive model description, assessment of the scientific content, limits of applicability, limitations and advantages of the model and any special features, possible improvements;

(iv) user oriented assessment which includes: the associated documentation, installation procedures, description of the user interface, guidance in selecting model options, guidance in the preparation of input data, checks to verify whether the model is used beyond its scope, clarity and flexibility of output results, unambiguous and understandable error messages, computational costs, possible improvements;

(v) verification of the code which can include: checks for internal consistency, comparisons with the analytical solutions and examination of the model behaviour in the limiting conditions such as the passive release;

(vi) validation of the model by comparing model predictions with observations which covers: the database selection, model characteristics, estimation of the model uncertainty, estimation of the uncertainty of the data, use of code comparison exercise, use of benchmark exercises, results of the validation, conclusions which may be drawn and recommendations.

It can be seen that the first two steps provide basic information. The other steps correspond to the three basic components of the model evaluation described in the MEG protocol. It is stated explicitly in the HGD protocol that a model developer or user preferably can perform the evaluation. The HGD evaluation protocol includes the guidance information on the steps for the evaluator. However it still leaves some choice in the techniques used in the specific evaluation steps in particular in the techniques of statistical validation, scientific assessment or user oriented assessment. The HGD protocol was tested in an open exercise which is described in the following section. The HGD Expert Group work reached its goals and after completing its duties formulated some recommendations for the future work. It postulated to organise a carefully planned independent evaluation exercise. It recommended development of general techniques for statistical, scientific and user oriented model evaluation.

To extend the previous evaluation work carried out by HGD Expert Group the CEC funded from 1996 to 1999 the SMEDIS project (Scientific Model Evaluation of Dense gas DIspersion Models) [60, 61]. The project objective was to develop and test a framework for scientific evaluation of models for dense gas dispersion in complex situations. The work was coordinated by the Health and Safety Executive (HSE) with two other main partners: 
the Cambridge Environmental Research Consultants (CERC) and Electricite de France (EdF). The model evaluation protocol developed for SMEDIS is consistent with the MEG protocol and makes use of the HGD protocol. It includes the following sections [60, 61]:

(i) general model description, which covers: the name, version number and release rate, short description of the model, model type, route of model into evaluation, history of model, quality assurance standards adopted, relations with other models, current model usage, hardware and software requirements, availability and costs;

(ii) scientific basis, which comprises: the specification of the source, specification of the environment, model physics and formulation, solution techniques, sources of model uncertainty, limits of applicability, special features, planned scientific developments;

(iii) user orientated aspects, which include: the user oriented documentation and help, installation procedures, description of the user interface, internal databases, guidance in selection of model options, assistance in the inputting data, error messages and checks on use of model beyond the scope, computational costs, clarity and flexibility of output results, suitability to users and usage, possible improvements, planned user oriented developments;

(iv) verification performed;

(v) validation performed;

(vi) conclusions.

Under each category up to two further levels of sub-categories are used and for many of them summary information is presented in a "check box" format for a quick overview. An instruction provides a scope of the assessment under each category. In the SMEDIS protocol the gathering of information, data sets for model evaluation and validation procedure are also described. To test the evaluation procedure the SMEDIS database was constructed and the validation exercise was organised. The database and exercise are described in the following section. The SMEDIS project reached its main goal which was to develop and test a framework for the scientific evaluation of models for dense gas dispersion in complex situations. The evaluation of models showed the strengths and the weaknesses of each model and this gives opportunity for model improvement. In the course of constructing the database it was found that there were significant gaps in the high quality experimental data sets for the scenarios with complex effects, in particular if wind tunnel experiments were excluded. Instantaneous releases featuring complex effects, stable atmospheric releases, situations where near field effects dominated (congested/confined releases) were in need of further experiments. Information on sensors accuracy and data uncertainty had not been always available.

In 2006 the new research project was started by HSE with the initiative of the Fire Protection Foundation (FPF) to adjust the experience gained in the quality evaluation of heavy gas dispersion models for the vapour dispersion models for safety analysis of LNG facilities [62-64]. The main objective of the work was to develop a tool for the evaluation of predictive models of dispersion of LNG spills on land and to review selected models. The work was divided in two parts. The tasks of the first part finished in 2007 included: the development of the protocol specific for the LNG dispersion models, selection of models and their classification, partial evaluation of some models excluding the statistical evaluation $[63,64]$. The development of the database was the main task of the second part of the project finished in 2009 [62]. It is described in the following section. In order to develop a specific protocol for LNG dispersion models the SMEDIS protocol for dense gas 
dispersion models was used as a starting point. The same concerns the questionnaire with a set of guidelines addressed to a model developer or proponents. These were modified taking into account their relevance to LNG vapour dispersion and so a specific version of the protocol was issued. The partial evaluation of the most common heavy gas dispersion models (DEGADIS, FEM3, FLUENT) was carried out. The results are not included in the report but they can be supplied by the authors on request.

\section{Statistical model evaluation exercises}

The work on statistical model evaluation was influenced by the experience in evaluation of atmospheric dispersion codes obtained during a decade of studies sponsored mainly by the American Meteorological Society (AMS) and US Environmental Protection Agency (EPA) [13, 15, 16, 65]. In 1991 the Panel on model evaluation was created to provide support in the work [66].

The information about the objective, scope and main results of the statistical evaluation exercises of heavy gas dispersion models is given. The first two exercises were carried out in the USA as independent projects. The other exercises were carried out by European institutions to test the procedures for the quality evaluation of heavy gas dispersion models.

The study on statistical evaluation of heavy gas dispersion models by Zapert, Londergan and Thistle $[67,68]$ was carried out for the US EPA within the program aimed to evaluate performance of several categories of air quality dispersion models by comparing observed and predicted concentrations using performance measures recommended by the AMS. The results of the work were issued in a technical report in 1991 [68]. In the study six heavy gas dispersion integral models (DEGADIS, AIRTIOX, CHARM, FOCUS, SAFEMODE, TRACE) and one shallow layer model (SLAB) were evaluated against the data from three field experimental programs (Goldfish, Burro, Desert Tortoise). The datasets were selected from EPA's Model Evaluation Support System (MESS). The characteristic of datasets, the references in which they are described and databases in which they are included are given in Table 1. The study involved statistical comparisons of predictions from each model with measurements from each database. Since all the experiments involved continuous releases it was decided to use the release duration as the averaging time for predictions. The observed and predicted maximum centreline concentrations at each receptor arc and a plume half width indicator at each arc were compared. The performance measures used included: the average difference, Fractional Bias (FB), Root Mean Square Error (RMSE), number of points for which observed and predicted values agree within a FACtor of two (FAC2) and correlation coefficient (R). They are defined in Table 2. In addition confidence intervals for average differences were checked based on the Student's t-test. In the published paper [68] only results with FB are described. The conclusion was that none of the models consistently demonstrated good performance for all three experimental programs. Two models, TRACE and CHARM, provided agreement within a factor of two for more than a half of the observed and predicted maximum values, while DEGADIS and SLAB each provide the best performance for one experimental program. It was noted that some of the developers disagreed with how their model was applied after the evaluation was completed and results reviewed. It was recommended that priority should be given to the collection and archival of a database to support dense gas model evaluation and that the future dense gas field experiments should include the presence of obstacles and provide additional documentation related to the 
release conditions. The study has provided the basis for objectively judging the performance of chosen models.

Table 1

Short characteristics of datasets from heavy gas dispersion experiments included in the databases created in Europe and the USA

\begin{tabular}{|c|c|c|}
\hline $\begin{array}{l}\text { 1. Name } \\
\text { 2. Institution } \\
\text { 3. Date } \\
\end{array}$ & $\begin{array}{l}\text { 1. Scale } \\
\text { 2. Location } \\
\text { 3. Material }\end{array}$ & $\begin{array}{l}\text { 1. References } \\
\text { 2. Databases }\end{array}$ \\
\hline $\begin{array}{l}\text { 1. Burro } \\
\text { 2. US Lawrence Livermore National } \\
\text { Laboratory (LLNL) } \\
\text { 3. } 1982\end{array}$ & $\begin{array}{l}\text { 1. field } \\
\text { 2. China Lake, USA } \\
\text { 3. LNG (Liquid Natural Gas) }\end{array}$ & $\begin{array}{l}\text { 1. [74-76] } \\
\text { 2. MESS, MDA, } \\
\text { REDIPHEM, SMEDIS, } \\
\text { LNG }\end{array}$ \\
\hline $\begin{array}{l}\text { 1. Coyote } \\
\text { 2. US LLNL } \\
\text { 3. } 1981 \\
\end{array}$ & \begin{tabular}{|l|} 
1. field \\
2. China lake, USA \\
3. LNG \\
\end{tabular} & $\begin{array}{l}\text { 1. [77, 78] } \\
\text { 2. MESS, MDA, } \\
\text { REDIPHEM, LNG }\end{array}$ \\
\hline $\begin{array}{l}\text { 1. Desert Tortoise } \\
\text { 2. US LLNL } \\
\text { 3. } 1983\end{array}$ & $\begin{array}{l}\text { 1. field } \\
\text { 2. Nevada, USA } \\
\text { 3. } \mathrm{NH}_{3} \\
\end{array}$ & $\begin{array}{l}\text { 1. [79, 80] } \\
\text { 2. MDA, REDIPHEM, } \\
\text { SMEDIS }\end{array}$ \\
\hline $\begin{array}{l}\text { 1. Falcon } \\
\text { 2. US LLNL } \\
\text { 3. } 1987\end{array}$ & $\begin{array}{l}\text { 1. field } \\
\text { 2. Nevada, USA } \\
\text { 3. LNG }\end{array}$ & $\begin{array}{l}\text { 1. }[81] \\
\text { 2. LNG }\end{array}$ \\
\hline $\begin{array}{l}\text { 1. Eagle } \\
\text { 2. US LLNL } \\
\text { 3. } 1983 \\
\end{array}$ & $\begin{array}{l}\text { 1. field } \\
\text { 2. Nevada, USA } \\
\text { 3. } \mathrm{NO}_{2} \\
\end{array}$ & $\begin{array}{l}\text { 1. [82] } \\
\text { 2. REDIPHEM }\end{array}$ \\
\hline $\begin{array}{l}\text { 1. Goldfish } \\
\text { 2. US LLNL } \\
\text { 3. } 1986\end{array}$ & $\begin{array}{l}\text { 1. field } \\
\text { 2. Nevada, USA } \\
\text { 3. HF }\end{array}$ & $\begin{array}{l}\text { 1. }[83] \\
\text { 2. MESS, MDA, LNG }\end{array}$ \\
\hline $\begin{array}{l}\text { 1. Maplin Sands } \\
\text { 2. Shell } \\
\text { 3. } 1980\end{array}$ & $\begin{array}{l}\text { 1. field } \\
\text { 2. Maplin Sands, USA } \\
\text { 3. LNG/LPG } \\
\end{array}$ & $\begin{array}{l}\text { 1. }[84,85] \\
\text { 2. MDA }\end{array}$ \\
\hline $\begin{array}{l}\text { 1. Thorney Island } \\
\text { 2. Health and Safety Executive (HSE), } \\
\text { GB } \\
\text { 3. } 1982-1984\end{array}$ & $\begin{array}{l}\text { 1. field } \\
\text { 2. Thorney Island, GB } \\
\text { 3. Freon }-12, \mathrm{~N}_{2}\end{array}$ & $\begin{array}{l}\text { 1. [86-91] } \\
\text { 2. MDA, CRAMD, SMEDIS }\end{array}$ \\
\hline $\begin{array}{l}\text { 1. FLADIS (research on the DISpersion } \\
\text { of two phase FLAshing releases) - } \\
\text { Riso } \\
\text { 2. Riso National Laboratory, Denmark } \\
\text { 3. 1993-1996 }\end{array}$ & $\begin{array}{l}\text { 1. field } \\
\text { 2. Landskrona, Sweden } \\
\text { 3. } \mathrm{NH}_{3}\end{array}$ & $\begin{array}{l}\text { 1. [92-95] } \\
\text { 2. REDIPHEM, SMEDIS }\end{array}$ \\
\hline $\begin{array}{l}\text { 1. BA-TUV } \\
\text { 2. Technischer Uberwachungs Verain } \\
\text { (TUV), Germany } \\
\text { 3. } 1988-1989\end{array}$ & $\begin{array}{l}\text { 1. field } \\
\text { 2. Lathen, Germany } \\
\text { 3. Propane }\end{array}$ & $\begin{array}{l}\text { 1. [96] } \\
\text { 2. REDIPHEM, SMEDIS }\end{array}$ \\
\hline $\begin{array}{l}\text { 1. BA-Hamburg } \\
\text { 2. Hamburg University, Germany } \\
\text { 3. } 1991\end{array}$ & $\begin{array}{l}\text { 1. wind tunnel } \\
\text { 2. Hamburg, Germany } \\
\text { 3. } \mathrm{SF}_{6}\end{array}$ & $\begin{array}{l}\text { 1. [97-99] } \\
\text { 2. REDIPHEM, SMEDIS, } \\
\text { LNG }\end{array}$ \\
\hline $\begin{array}{l}\text { 1. BA-TNO } \\
\text { 2. TNO (Netherlands Organisation for the } \\
\text { Applied Scientific Research), The } \\
\text { Netherlands } \\
\text { 3. 1988-1990 }\end{array}$ & $\begin{array}{l}\text { 1. wind tunnel } \\
\text { 2. Apeldoorn, The Netherlands } \\
\text { 3. } \mathrm{SF}_{6}\end{array}$ & $\begin{array}{l}\text { 1. [100, 101] } \\
\text { 2. REDIPHEM, SMEDIS, } \\
\text { LNG }\end{array}$ \\
\hline $\begin{array}{l}\text { 1. STEP FLADIS-TNO } \\
\text { 2. TNO } \\
\text { 3. } 1992\end{array}$ & $\begin{array}{l}\text { 1. wind tunnel } \\
\text { 2. Apeldoorn, The Netherlands } \\
\text { 3. } \mathrm{SF}_{6}\end{array}$ & $\begin{array}{l}\text { 1. }[102] \\
\text { 2. REDIPHEM }\end{array}$ \\
\hline
\end{tabular}




\begin{tabular}{|c|c|c|}
\hline $\begin{array}{l}\text { 1. WSL Repeat variability } \\
\text { 2. Warren Spring Laboratory (WSL), GB } \\
\text { 3. 1988-1991 }\end{array}$ & \begin{tabular}{|l} 
1. wind tunnel \\
2. Stevenage, GB \\
3. isothermal release of Thorney \\
Island type
\end{tabular} & $\begin{array}{l}\text { 1. }[103,104] \\
\text { 2. REDIPHEM }\end{array}$ \\
\hline $\begin{array}{l}\text { 1. EMU-ENFLO (Evaluation of 2. Model } \\
\text { Uncertainty, ENvironmental FLOw } \\
\text { research center) } \\
\text { 2. University of Surrey, GB } \\
\text { 3. } 1997\end{array}$ & $\begin{array}{l}\text { 1. wind tunnel } \\
\text { 2. Surrey, GB } \\
\text { 3. Krypton }\end{array}$ & $\begin{array}{l}\text { 1. [105] } \\
\text { 2. SMEDIS }\end{array}$ \\
\hline $\begin{array}{l}\text { 1. CHRC (Chemical Hazards Research } \\
\text { Centre) } \\
\text { 2. University of Arkansas, USA } \\
\text { 3. } 2006 \\
\end{array}$ & $\begin{array}{l}\text { 1. wind tunnel } \\
\text { 2. Arkansas, USA } \\
\text { 3. } \mathrm{CO}_{2}\end{array}$ & $\begin{array}{l}\text { 1. [106] } \\
\text { 2. LNG }\end{array}$ \\
\hline
\end{tabular}

The statistical evaluation exercise by Sigma Research Corporation (SRC) was carried out for the US Air Force and the American Petroleum Institute (API). The work of Hanna, Strimaitis and Chang [69-71] has been regarded as the first model evaluation project where standard objective quantitative means of evaluating heavy gas dispersion models were applied. It lasted four years and was finished in 1993. It covered three components: the creation of a Modeller's Data Archive (MDA) with data sets from experiments, selection of model evaluation statistics and development of software and selection of appropriate model sensitivity studies. Fifteen models were selected for the study. These were heavy gas dispersion models (empirical: $\mathrm{B}$ and McQ model, integral: DEGADIS, HEGADAS, HGSYSTEM, AIRTOX, CHARM, FOCUS, FAST, TRACE, GASTAR models, and shallow layer: SLAB model) and Gaussian type models for neutrally buoyant pollutants (INPUFF, OB/DG, GPM models). In order to carry out multiple runs of these models a MDA was created. It contains the data from the field experiments of continuous releases of heavy gases (Coyote, Desert Tortoise, Goldfish, Maplin Sands, Thorney Island), instantaneous releases of heavy gases (Thorney Island) and continuous releases of gases of neutral buoyancy (Hanford Kr 85, Praire Grass) (Table 1). More information on the MDA is given in the following section. The performance measures used in the study covered: Geometric Mean bias (MG), Geometric mean Variance (VG) and two measures used by Zapert, Londergan and Thistle: R and FAC2 (Table 2). In addition confidence limits on MG was estimated by bootstrap or jacknife resampling methods. The performance measures were calculated from modelled and observed plume centreline concentrations and modelled and observed cloud widths. Statistical evaluation was carried out separately for three distinct groups of data. The studies covered the investigation of trends in the performance of models as a function of several parameters such as the atmospheric stability and wind speed. It was stressed that scientific evaluation of models was at least equally important. Consequently evaluation of vertical dispersion and sensitivity of model predictions to variations of averaging times and changes in the surface roughness was carried out for some models. It was found that B and McQ, CHARM, GASTAR, HEGADAS, HGSYSTEM, PHAST, SLAB, and TRACE models exhibited the most consistent predictions of the plume centreline concentration. The dense gas models tended to overpredict the plume widths and underpredict the plume depths by about a factor of two. All models except GASTAR, TRACE, and DEGADIS performed fairly well with the continuous passive gas data sets. None of the tested models was able to reproduce the observed variation of concentrations with averaging time. The predictions of concentrations were weakly sensitive to the change 
in roughness length. It was noted that in some of the chosen models at least some of the data were used to derive the model parameters so the principle of model evaluation with independent data was violated.

Table 2

Statistical performance measures used in quality evaluation of heavy gas dispersion models. $C_{o}, C_{p}$ are the observed and predicted by the model values of the physical parameter, $<>$ denotes averaging over the set of $N$ points or $N$ arcs

\begin{tabular}{|c|c|c|}
\hline $\begin{array}{c}\text { Statistical } \\
\text { parameter name }\end{array}$ & Definition & References \\
\hline $\begin{array}{c}\text { Bias, Average } \\
\text { difference }\end{array}$ & $B=\left\langle C_{o}-C_{p}\right\rangle$ & [67] \\
\hline Fractional Bias & $F B=2 \frac{\left\langle C_{o}\right\rangle-\left\langle C_{p}\right\rangle}{\left\langle C_{p}\right\rangle+\left\langle C_{o}\right\rangle}$ & [67] \\
\hline $\begin{array}{c}\text { Root Mean Square } \\
\text { Error }\end{array}$ & $R M S E=\left(\left\langle\left(C_{o}-C_{p}\right)^{2}\right\rangle\right)^{1 / 2}$ & [67] \\
\hline Mean Relative Bias & $M R B=\left\langle 2 \frac{C_{o}-C_{p}}{C_{p}+C_{o}}\right\rangle$ & {$[55,57,58,60-63]$} \\
\hline $\begin{array}{l}\text { Mean Relative } \\
\text { Square Error }\end{array}$ & $M R S E=\left\langle 4\left(\frac{C_{o}-C_{p}}{C_{p}+C_{o}}\right)^{2}\right\rangle$ & {$[58,60-63]$} \\
\hline $\begin{array}{c}\text { Geometric Mean } \\
\text { bias }\end{array}$ & $M G=\exp \left\langle\ln \left(C_{o} / C_{p}\right)\right\rangle$ & {$[58,60-63,69-71]$} \\
\hline $\begin{array}{l}\text { Geometric mean } \\
\text { Variance }\end{array}$ & $V G=\exp \left[\left\langle\ln \left(C_{o} / C_{p}\right)\right\rangle^{2}\right]$ & {$[58,60-63,69-71]$} \\
\hline FActor of $n$ & $F A n=\frac{N_{1 / n<C p / C o<n}}{N}$ & {$[58,60-63,67,69-71]$} \\
\hline $\begin{array}{c}\text { Fraction of } \\
\text { OvErprediction }\end{array}$ & $F O E X=\frac{N_{C p>C o}}{N}-0,5$ & [58] \\
\hline $\begin{array}{l}\text { CoRrelation } \\
\text { coefficient }\end{array}$ & $R=\frac{\left\langle\left(C_{o}-\left\langle C_{o}\right\rangle\right)\left(C_{p}-\left\langle C_{p}\right\rangle\right)\right\rangle}{\sqrt{\left(\left\langle C_{o}^{2}-\left\langle C_{o}\right\rangle^{2}\right\rangle\left\langle C_{p}^{2}-\left\langle C_{p}\right\rangle^{2}\right\rangle\right.}}$ & {$[58,60-63,67,69-71]$} \\
\hline
\end{tabular}

The evaluation exercise carried out within the REDIPHEM project was directed to the formulation of guidelines on statistical evaluation of heavy gas dispersion models [58]. The tests were restricted to continuous dense gas releases over flat and generally undisturbed terrain. The data from the field experiments (BA-TUV, FLADIS-Riso, Desert Tortoise, Coyote) and wind tunnel experiments (BA-TNO and BA-Hamburg) were used. They were extracted from the REDIPHEM database created to fulfil the needs of the project. It is described in the following section. Four simple models were selected for the study: one empirical heavy gas dispersion model ( $\mathrm{B}$ and McQ model) and three variations of the Gaussian plume model for neutrally buoyant pollutants (the original Gaussian plume model used in regulatory calculations in the Netherlands and two versions of this model with modified dispersion parameters). Two different evaluation procedures were used. In the first 
case data paired in time and space were compared. In the second case the observed maximum concentrations at certain distances together with a measure of the plume width were used. Selected performance measures included the set of statistics earlier used by Hanna et al [70] such as the MG, VG, and FAn (FActor of $n)$ and three statistics proposed by the authors of the project: the MRB (Mean Relative Bias), MRSE (Mean Relative Square Error) and FOEX (Fraction of OvErprediction) (Table 2). It was found that ranking and the performance of the heavy gas dispersion models depended substantially on the evaluation procedure, the data sets used and to a somewhat lesser degree on the performance measure selected. The two selected procedures had both advantages and disadvantages. Using the maximum concentrations one should always take into account the plume width. Using the spatially distributed data there was substantial disagreement between the predicted and measured concentrations due to differences in the localisation of the predicted and observed plume path. For the future use in statistical evaluation a combination of the MRB, MRSE and FA2 was suggested. It was stressed that in model quality evaluation the scientific evaluation was at least equally important.

The exercise carried out by the HGD Expert Group to test the protocol had an open character [57]. It means that participation in the exercise was on a voluntary basis. Several European teams or individuals participated. Two data sets dealing with the dispersion in the flat terrain extracted from the REDIPHEM database were used in the evaluation exercise: the BA-TUV 55 field measurements and the BA-TNO wind tunnel observations (Table 1). As a statistical performance measure the MRB was considered (Table 2). The results were presented anonymously without connecting them with specific models. They show that the predictions of the models agreed broadly within a factor of two with the observations with the general tendency to overestimation. It needs to be mentioned that at this time there was a limited experience on statistical evaluation of heavy gas dispersion models obtained mainly in the US and the protocol did not recommend any procedure.

In the validation exercise which was organised to test the evaluation procedure developed during the SMEDIS project $[60,61]$ the datasets from the REDIPHEM database and the datasets from the field experiments in Thorney Island and from the wind tunnel experiments named EMU-ENFLO (Evaluation of Model Uncertainty, ENvironmental FLOw research centre) were used (Table 1). The SMEDIS database was created to contain and classify these data based on the following features: source type, gas density, atmospheric conditions, complex effects. The exercise was carried out for the 30 cases however the number of the cases of which each model simulated was depended on the type of the model. For one empirical model (B and McQ model) and thirteen integral models (AERCLOUD, DEGADIS, DRIFT, EOLE, ESCAPE, GASTAR, GreAT, HAGAR, HGSystem, OHRAT, PHAST/UDM, SLUMP, WHAZAN/HVYCLD) all the cases were simulated, but for five shallow layer models (DISPLAY-1, DISPLAY-2, SLAB, SLAM, TWODEE) and eight CFD models (ADREA-HF, CFX, COBRA, FLACS, FLUENT, KAMELEON FireEx 98, MERCURE- GL, STAR-CD) about 50 and $20 \%$ of the cases were checked. In the selection of the validation procedure and the performance measures the suggestions from the validation exercise carried out under the REDIPHEM project were used [58]. Two techniques were used in the validation procedure. In the pointwise comparisons the cloud parameters at individual points were considered: for continuous releases the time averaged concentrations were taken into account and for instantaneous releases the doses, cloud arrival and departure times were used. In the arcwise comparisons 
the parameters taken over sensor arcs were considered: for continuous releases the maximum concentrations and plume widths were taken into account and for instantaneous releases maximum doses, maximum concentrations, times for maximum concentrations, cloud widths, cloud arrival and departure times were used. As the main performance measures the MRB, MRSE, FAn, MG and VG were considered based on the experience from the earlier exercises (Table 2). The results were presented in terms of the model classes and the alternatives of complex effects (aerosol, complex terrain, obstacles, congestion or confinement, none). They were not used to rank the models. The preliminary results in which only a part of model simulations were used indicated that the arcwise comparison showed more optimistic view of model performance than the pointwise comparison when complex effects were present and that in general statistical performance was better for more sophisticated models.

\section{Databases with experimental data on heavy gas dispersion}

The databases including the data on heavy gas dispersion have been usually created to support the exercises on statistical evaluation of heavy gas dispersion models. The databases have different structure and to some extent different content. They are equipped with different tools/facilities to collect, process and present the data.

The MDA was created during the statistical evaluation exercise carried out by Hanna, Chang and Strimaitsis [69-71]. The structure of MDA is the following: information defining the experiment and trial, a list of several chemical properties of the substance released, physical properties of the release, meteorological data (time averaged), site information, information related to the model application to a particular experiment and trial such as concentration averaging time, concentration of interest for specifying lateral extent of the cloud, receptor heights and distances, files of observed maximum concentrations for distances and averaging times contained in MDA. The MDA includes eight dissimilar datasets from the field experiments. These datasets consider continuous dense gas releases (Burro, Coyote, Desert Tortoise, Goldfish, Maplin Sands, Thorney Island), instantaneous dense gas releases (Thorney Island) and continuous non-buoyant pollution releases (Hanford Kr 85, Praire Grass). More information on the datasets is presented in Table 1. The MDA is available from the authors.

The REDIPHEM database was created during the project known under the same name by Nielsen and Ott [72]. It is organised into files containing different kinds of information. The description of experiments is divided into quantitative release specifications, meteorological conditions and comments in text files. The instrumentation is described by lists of sensor positions and text files describing the signal types and sensor characteristics. It differs substantially from the MDA database in that it contains the full time series of meteorological and concentration data. These time series can be visualised, processed and exported using the REDIPHEM data browser. The database focus on data from experiments performed in relation to the CEC sponsored research and some data obtained in the USA. It includes the data sets from the field experiments (Burro, Coyote, Desert Tortoise, Eagle, FLADIS-Riso, BA-TUV) and wind tunnel experiments (BA-Hamburg, BA-TNO, STEP FLADIS-TNO, WSL repeat variability) (Table 1). The REDIPHEM database is freely available via internet from RISO.

At the same time as the REDIPHEM project another project named DATBASE was carried out [73]. It was coordinated by the TRI (Tesca Research and Innovation) and VTT 
(Valtion Teknillinen Tutkimuskeskus, in Finish: Technical research centre of Finland). The objective of it was to collect available data on source term dispersion and complex terrain experiments funded by CEC and design and construct a prototype database called CRAMD (Chemical Risk Assessment Modelling Database) for a wider group of users then the REDIPHEM database. The CRAMD database has the object oriented structure. It includes all sorts of facilities to extract, present and use the data. It is possible to extend it to other areas of model validation. Initially there were some difficulties with the data collection due to lack of response from the CEC projects. The cooperation with the REDIPHEM project and direct approaching of the organisations from the UK and the USA changed that. As a result the data collected within the project include all the data from the REDIPHEM database and in addition several datasets supplied directly by the organisations approached. For the purpose of demonstrating the capabilities of the prototype database three datasets were selected: Thorney Island field trials, lidar data for elevated and ground level clouds and wind tunnel studies of surface roughness effects on dense gas dispersion. The authors of the project plan to incorporate unused data into the database at a later date.

The SMEDIS database was created as part of the project known under the same acronym $[60,61]$. It includes the data from the REDIPHEM database and in addition the data sets from Thorney Island and EMU-ENFLO experiments (Table 2). It was constructed with the focus on datasets from the experiments from the heavy gas dispersion in complex situations. The scenarios are grouped into a four dimensional matrix in which each dimension represented specific aspect of model usage for which up to five alternatives were specified. These aspects were the following: source type (instantaneous/continuous), gas density (strong/weak density effects), atmospheric conditions (stable/neutral or unstable/low or no wind), complex effects (aerosol/terrain/obstacles/congestion or confinement/none). Although not all of the alternatives were covered by the measurements, there is a sufficient spread of conditions for which data sets are of adequate quality. The data for each case are prepared in the Excel workbook. There is one workbook per case containing the data describing the test set up together with concentration measurements (and others) against which the model predictions are to be compared. The authors of the project have intended to make the database available to other researchers.

The LNG model validation database was created in the second part of the research project on evaluation of the vapour dispersion models for safety analysis of LNG facilities [62]. Specific test cases for inclusion in the LNG model validation database were selected from the field experiments (Maplin Sands, Burro, Coyote, Falcon, Thorney Island) and wind tunnel experiments (Chemical Hazard Research Centre, BA-Hamburg, BA-TNO). Most of the data were obtained from REDIPHEM or MDA databases (Table 1). The database is contained in a single Microsoft Excel 2003 workbook. The first sheet in this workbook is a key which summarises the set cases in the database. Each test case occupies its own worksheet. These worksheets are of broadly similar construction but the exact form depends on the nature on the trial and test data. They contain: the trial name, test identifier, date of test, origin of data of inclusion, test description, substance released, release conditions, atmospheric conditions, terrain and obstacles, physical comparison parameters, units. The physical comparison parameters are the following: maximum concentration across an arc at radius/distance $\mathrm{x}$ from the source, cloud width across the arc at radius/ distance $\mathrm{x}$ from the source, concentration at specific sensor location. These parameters are provided for short and long time average. The first parameter is typically of the order of one 
second, the second parameter is comparable to the duration of the release. Each work sheet contains an area for model output data to be added. The model output data is used in the calculation of statistical performance measures. They are calculated automatically through macros embedded in the workbook. The calculations are split into two groups which are characteristic of the presence or absence of obstacles. To the set of statistical performance measures from the SMEDIS project (MRB, MRSE, FAC2, MG, VG) the modelled shortest distance to the same maximum concentration as found experimentally on arc is added (Table 2). This may need to be revised. It was recommended to consider a separate model evaluation exercise to assess the applicability of source models for LNG dispersion and the performance of the full evaluation of number of models and refinement of the protocol.

There are much more experimental data related to the subject than these included in the databases [74-106]. This concerns the data from the experiments carried out in the seventies or the early eighties reviewed among others by Lees [10] and the experiments carried out within the Petroleum Environmental Research Forum project [107-114] and some others $[115,116]$.

\section{Conclusions}

In the seventies and eighties there was a limited experience in the model quality evaluation. This concerned also the heavy gas dispersion models. Since the early 1990s there have been a number of projects mainly in Europe and the USA in which quality evaluation of technical models with the focus on heavy gas dispersion models is the main subject. As a result of these projects much experience has been gained and reasonable consensus has been built up for this group of models concerning the model quality evaluation. It seems that the scientific model evaluation procedure developed within the SMEDIS project, being consistent with the HGDEG and MEG propositions will find an acceptance within the community of researchers, users and decision makers. Its employment will allow to care for model quality at an early stage and will make it easier to choose the right model to perform calculations for a specific scenario. It is an advantage that some of the databases with the field and wind tunnel data related to the subject (MDA, REDIPHEM, SMEDIS) have been made or are promised by their authors to be available to the model developers and users. It is important that in the future work in this area the postulates formulated by the researches are taken into account. In particular the gaps in the measurement data should be removed by initiating more experiments in complex conditions. There is a need to disseminate the knowledge on the quality evaluation of heavy gas dispersion models and use it in practical tasks in the community of researchers, users and decision makers in Poland, especially that the Polish side has not participated in the described European Union projects.

\section{References}

[1] Markiewicz MT. Ecol Chem Eng. S. 2012;19(3):297-314. DOI: 10.2478/v10216-011-0022-y.

[2] Mercer A, Bartholome C, Carissimo B, Duijm N, Giesbrecht H. Heavy Gas Dispersion Expert Group, Model Evaluation Group Final Report. Belgium: Directorate of Research, Science and Development; 1999.

[3] Mercer A, Bartholome C, Carissimo B, Duijm N, Giebrecht H. I J Environ Pollut. 1997;338-345. DOI: 10.1504/IJEP.1997.028182.

[4] Britter R. Recent research on the dispersion of hazardous materials. EUR 18198 EN. Brussels, Belgium: Council of European Communities; 1998. 
[5] Hanna SR, Drivas PJ. Guidelines for Use of Vapour Cloud Dispersion Models. New York: Center for Chemical Process Safety, Institute of Chemical Engineers; 1989.

[6] Koopman RP, Ermak DL. J. Hazard Mater. 2007;140:412-428. DOI: 10.1016/j.jhazmat.2006.10.042.

[7] Luketa-Hanlin A, Koopman RP, Ermak L. J Hazard Mater. 2007;140:504-517. DOI: 10.1016/j.jhazmat.2006.10.023.

[8] Markiewicz M. Modelling of the heavy gas dispersion. In: Borysiewicz M, Potemski S, editors. Modelling and Techniques for Health and Environment Hazard Assessment and Management. Otwock, Poland: Institute of Atomic Energy; 2006:279-302.

[9] Markiewicz MT. Modelling of heavy gas dispersion in Poland. In: Pawlowski L, Dudzinska MR, Pawlowski A, editors. Environmental Engineering, London: Taylor and Francis; 2007:371-374.

[10] Emission and dispersion. In: Lees FP, editor. Loss Prevention in the Process Industries. London: Butterworths; 2005.

[11] Chang JC, Hanna SR. Meteorol Atmos Phys. 2004; 87:167-196. DOI: 10.1007/S00703-003-0070-7.

[12] Markiewicz MT. Fundamentals of the Pollution Dispersion in the Atmosphere. Warsaw: Warsaw Technological University Printing Office; 2004 (in Polish).

[13] Fox DG. Bull Am Met Soc. 1984;65:27-3; DOI: http://dx.doi.org/10.1175/15200477(1984)065<0027:UIAQM>2.0.CO;2.

[14] Hill MD. Verification and Validation of NRPB Models for Calculating Rates of Radionuclide Transfer through the Environment. Chilton, UK: National Radiological Protection Board; 1988.

[15] Hill MD. In: Desmet G, editor, Reliability of Radioactive Transfer Models. London and New York: Elsevier Publishing Company; 1988:15-21. DOI: 10.1007/978-94-009-1369-1-2.

[16] US EPA, Interim procedures for evaluating air quality models (revised), EPA-450/4-84-023, OAQPS, US Environmental Protection Agency, Research Triangle Park, NC, 1984.

[17] Willmott CJ, Ackleson SG, Davis RE, Feddema JJ, Klink KM, Legates DR, et al. J Geophys Res. 1985;90(C5):8995-9005.

[18] Venkatram A. Bound Layer Meteor. 1983;27:186-196.

[19] Weil JC, Sykes RI, Venkatram A. J Appl Meteor. 1983;31(10):1121-1145.

[20] Galmarini S, Bianconi R, Klug W, Mikkelsen T, Addis R, Andronopoulos S, et al. Atmos Environ. 2004;38(28):4607-4617. DOI: 10.1016/j.atmenv.2004.05.030.

[21] Olesen HR, Chang JC. Int J Environ Pollut. 2010;40:175-183.

[22] Olesen HR. User's Guide to the Model Validation Kit. Research Note No. 226; 2006.

[23] Cuvelier C, Thunis P, Vautard R, Amann M, Bessagnet B, Bedogni M, et al. Atmos Eviron. 2007;41(1):189-207. DOI: 10.1016/j.atmosenv.20006.07.036.

[24] Irwin JS, Civerolo K, Hogrefe C, Appel W, Foley K, Swall J. Atmos Environ. 2008;42:5403-5412. DOI: 10.1016/j.atmosenv.2008.02.046.

[25] Dennis R, Fox T, Fuentes M, Gilliland A, Hanna S, Hogrefe C, et al. Environ Fluid Mech. 2010; http://dx.doi.org/10.1007s10652-009-9163-2.

[26] Carslaw DC, Ropkins K. Environ Model Soft. 2011; http://dx.doi.org/10.1016/j.envsoft.2011.09.008.

[27] Borrego C, Monteiro A, Ferreira J, Miranda AI, Costa AM, Carvalho AC, et al. Environ Int. 2008;34:613-620. DOI: 10.1016/j.envint.2007.12.005.

[28] Venkatram A. Atmos Environ. 2008;42:6862-6868. DOI: 10.1016/j.atmosenv.2008.04.043.

[29] Overview of tools and methods for meteorological and air pollution mesoscale model evaluation and user training. Joint Report of COST Action 728 and GURME. Schlutzen KH, Sokhi RS, editors. Geneva: World Meteorological Organization; 2008.

[30] Dennis R, Fox T, Fuentes M, Gilliland A, Hanna S, Hogrefe Ch, et al. Environ Fluid Mech. 2010;10:471-489. DOI: 10.1007/s10652-009-9163-2

[31] Appel KW, Gilliam RC, Davis N, Zubrow A, Howard SC. Environ Model Soft. 2011;26:434-443. DOI: 10.101016/j.envsoft.2010.09.007.

[32] Thunis P, Georgieva E, Pederzoli A. Environ Model Soft. 2012;38:220-230. DOI: doi.org/10.1016/j.envwsoft.2012.06.005.

[33] Thunis P, Pederzoli A, Pernigotti D. Atmos Environ. 2012;59:476-482. DOI: http://dx.doi.org/10.1016/j.atmosenv.2012.05.043.

[34] Meroney R. J Wind Eng Ind Aerod. 2012;104-106:500-508. DOI: 10.1016/j.jweia.2012.01.001.

[35] Meroney R. Atmos Environ. 2012; 54:706-713. DOI:10.1016/j.atmosenv.2012.01.038.

[36] Sun B, Utikar RP, Pareek VK, Guo K. J Loss Prev Proc Ind. 2013;26:117-128. DOI: http://dx.doi.org/10.1016/j.jlp.2012.10.002. 
[37] Hanna S, Britter R, Argenta E, Chang J. J Hazard Mater. 2012;213-214:406-412. DOI: 10.1016/j.jhazmat2012.02.013.

[38] Ruj B, Chatterjee PK. J Loss Prev Proc Ind. 2012;650-653. DOI: 10.1016/j.jlp.2012.01.002.

[39] Havens J, Walker HJ, Spicer T. J Hazard Mater. 2012;34:33-34. DOI: http://dx.doi.org/10.1016/j.jhazmat.2012.06.055.

[40] Labovsky J, Jelemensky L. J Loss Prev Proc Ind. 2011;24:166-177. DOI: 10.1016/j.jlp.2010.12.005.

[41] Pontiggia M, Landucci G, Busini V, Derudi M, Alba M, Scaioni M, et al. Atmos Environ. 2011;45:3913-3923. DOI: 10.1016/j.atmosenvi.2011.04.071.

[42] Tauseef SM, Rashtchian D, Abbasi SA. Loss Prev Proc Ind. 2011;24:371-376. DOI: 10.1016/j.jlp.2011.01.014.

[43] Sciargali F, Grisafi F, Busciglio A, Brucato A. J Hazard Mater. 2011;197:285-293. DOI: 10.1016/j.jhazmat.2011.09.086.

[44] Sanchez EY, Lerner JEC, Porta A, Jacovkis PM. Atmos Environ. 2013;64:47-55. DOI: http://dx.doi.org/10.1016/j.atmosenv.2012.09.037.

[45] Vilchez JA, Villafane D, Casal J. J Loss Prev Proc Ind. 2013;246-247:181-188. DOI: http://dx.doi.org/10.1016/j.jhazmat.2012.11.045

[46] Mercer A. Methods of validating models of dense gas dispersion: a review. In: Puttock JS, editor. Stably Stratified Flows and Dense Gas Dispersion. Oxford, UK: Clarendon Press; 169-203, 1988.

[47] Fay JA, Ranck D. Atmos Environ. 1983;17:239-248. DOI: http://dx.doi.org/10.1016/0004-6981(83)90039_ 2 .

[48] Wheatley CJ, Webber DM. Aspects of the dispersion of heavier than air vapour related to cloud gas explosions. Report EUR-9592, 1984.

[49] Woodward L, Havens WC, Mcbride JA, Taft JR. J Hazard Mater. 1982;6:161-180. DOI: 10.1016/0304-3894(82)80038-1.

[50] Ermak DL, Chan ST, Morgan DL, Morris LK. J Hazard Mater. 1982;6:129-160. DOI: 10.1016/0304-3894(82)80037-X.

[51] Ermak DL, Rodean HC, Lange R, Chan ST. A survey of denser than air atmospheric dispersion models. UCRL-21024. Livermore, California: Lawrence Livermore National Laboratory; 1988.

[52] Havens JA, Spicer TO, Schreurs DP. Evaluation of 3D hydrodynamic computer models for prediction LNG vapour dispersion in the atmosphere. Report GRI-87-0173. Chicago: Gas Research Institute; 1987.

[53] Ermak DL, Merry MH. A methodology for evaluating heavy gas dispersion models. Lawrence Livermore National Laboratory for Air Force Engineering and Services Center Report ESL-TR-88-37, Tyndal AFB, Florida; 1988.

[54] Britter RE. The evaluation of technical models used for major-accident hazard installations. EUR 14774, Brussels, Belgium: CEC; 1991.

[55] Petersen KE. J Hazard Mater. 1999;65:37-41. PII S034-3894(98)00252-0.

[56] Vergison E. J Hazard Mater. 1996;49:281-297. PII S034-3894(96)01746-3.

[57] Duijm NJ., Carissimo B, Mercer A, Bartholome C, Giesbrecht H. J Hazard Mater. 1997;56:273-285. PII S50304-3839(97)00069-1. DOI: http://dx.doi.org/10.1016/S0304-3894(97)00069-1.

[58] Duijm NJ, Ott S, Nielsen M. J Loss Prev Proc Ind. 1996;9:23-338. DOI: http;//dx.doi.org/10.1016/0950-4230(96)00027-7.

[59] Bakkum E. Heavy gas dispersion evaluation protocol, REDIPHEM Project Report. Appeldorn: TNO; 1994.

[60] Carissimo B, Jagger SF, Daish NC, Halford A, Selmer-Olsen S, Perroux JM, et al. Int J Environ Pollut. 2001;16(1-6):614-629. DOI: 10.1504/IJEP.2001.000654.

[61] Daish NC, Britter RE, Linden PF, Jagger SF, Carissimo B. I J Environ Pollut. 2000;14:39-51. DOI: 10.1504/IJEP.2000.000525.

[62] Coldrick S, Lea CJ, Ivings MJ. Guide to the LNG model validation database, HSE Report, Fire Protection Research Foundation; 2010. www.npfa.org/foundation.

[63] Ivings MJ, Jagger SF, Lea CJ, Webber DM. Evaluating vapour dispersion models for safety analysis of LNG facilities research project. HSE Report. Fire Protection Research Foundation; 2007. www.nfpa.org.foundation.

[64] Ivings MJ, Lea CJ, Webber DM, Jagger SF, Coldrick S. A protocol for the evaluations of LNG vapour dispersion models. J Loss Prev Proc Ind. 2013;26:157-163. DOI: //dx.doi.org/10.1016/j.jlp.2012.10.005.

[65] Weil JC, Sykes R, Venkatram A. J Appl Meteor. 1992;31:1121-1145. DOI: http://dx.doi.org/10.1175/1520-0450(1992)031<1121:EAQMRA>2.0.CO;2.

[66] Hanna SR, Chatwin P, Chikhliwala E, Londergan R, Spicer T, Weil J. Plant Oper Prog. 1992;11:2-5. DOI: 10.1002/prsb.720110106. 
[67] Zapert JG, Londergan RJ, Thistle H. Evaluation of dense gas simulation models. US EPA Report, EPA 450/4-90-018, North Carolina: Research Triangle Park; 1991.

[68] Touma JS, Cox WM, Thistle H, Zapert JG. J Appl Meteor. 1995;34:603. DOI: hhtp://dx.doi.org/10.1175/1520-0450(1995)034<0603:PEODGD>2.0.CO;2.

[69] Hanna SR, Chang JC, Strimaitis DG. Atmos Environ. 1993;27A(15):2265-2285.

[70] Hanna SR, Strimaitis DG, Chang JC. J Hazard Mater. 1991;26:127-158.

[71] Hanna SR, Strimaitis DG, Chang JC. Hazard response modelling uncertainty. Evaluation of commonly used hazardous gas dispersion models. Final report. Westford, MA, USA: Sigma Research; 1991.

[72] Nielsen M, Ott S. A collection of data from dense gas experiments. Report R-845. Roskilde, Denmark: Riso National Laboratory; 1995.

[73] Kako R, Lansipuro H, Kujansuu E, Lancia A, Gambirasio A, Ziomas IC, et al. J Loss Prev Proc Ind. 1996;9:401-411.

[74] Koopman RP, Baker RT, Cederwall RT, Goldwire HC, Hogan WJ, Kamppinen LM, et al. Burro series data report LLNL/NWC, LNG Spill Tests, UICD 19075. Livermore, California: Lawrence Livermore National Laboratories; 1982.

[75] Koopman RP, Cederwall RT, Ermak DL, Goldwire HC, Hogan WJ, McClure JW, et al. Analysis of Burro series $40 \mathrm{~m}^{3}$ LNG spill experiments. J Hazard Mater. 1982;6:43-83. DOI: 10.1016/0304-3894(82)80034-4.

[76] Koopman RP, Ermak DL, Chan T. Atmos Environ. 1989;23:731-745. DOI: 10.1016/0004-6981(89)90475-7.

[77] Goldwire HC, Morris LK, Kamppinen L, Kiefar RD, Lind CD, Urtiew PA. Coyote series data report, LLNL/NWC, LNG spill tests. Livermore, California: Lawrence Livermore National Laboratory; 1983.

[78] Goldwire HC, Rodean HC, Cederwall RP, Kansa GJ, Koopman RP, McClure JW, et al. Coyote series data report, LLNL/NWC, LNG spill tests, Dispersion, vapour burn and rapid transition. Livermore, California: Lawrence Livermore National Laboratories; 1983.

[79] Goldwire HC, McRae TG, Johnson GW, Hippie DL, Koopman RP, McClure JW, et al. Desert Tortoise second data report: 1983 pressurised ammonia spills. UCID-20562. Livermore, California: Lawrence Livermore National Laboratory; 1985.

[80] Koopman RP, McRae TG, Goldwire HC, Ermak DL, Kansa EJ. Results of recent large scale NH3 and N2O4 dispersion experiments. In: Hartwig S, editor. Heavy Gas and Risk Assessment. D. Reidel Publishing; 1986:137-156.

[81] Brown TC, Cederwall RT, Ermak DL, Koopman RP, McClure TC, Morris LK. Falcon series data report. Livermore, California: Lawrence Livermore National Laboratory; 1989.

[82] McRae TG, Cederwall RT, Ermak DL, Goldwire JJ, Hipple DL, Johnson GW, et al. Eagle series data report: 1983 Nitrogen tetroxide spills, CID-20063. Livermore, California: Lawrence Livermore National Laboratory; 1984.

[83] Blewitt DN, Yohn JF, Koopman RP, Brown TC. Conduct of adhydrous hydrofluoric acid spill experiment. In: Proceedings of the International Conference on Vapour Cloud Modelling. New York: AICHE; 1987:1-38.

[84] Puttock JS, Colenbrander GW, Blackmoore DR. Maplin Sands experiments 1980: Dispersion results from continuous releases of refrigerated liquid propane and LNG. In: Wispelaere CD, editor. Air Pollution Modelling and its Application. New York: Plenum Press; 1982;4:353-378.

[85] Puttock JS, Blackmore DR, Colenbrander GW. J Hazard Mater. 1982;6:13-41.

[86] McQuaid J, Roebuck B. Large scale field trials on dense vapour dispersion. Report 10029. Brussels: Health and Safety Executive; 1985.

[87] McQuaid J, Roebuck B, Wilde DG. Saf Therm Water React. 1985; 179-189. DOI: 10.1007/978-94-009-4972-0-18.

[88] McQuaid J. Large scale experiments on the dispersion of heavy gas clouds. In: Ooms G, Tennekes H, editors. Atmospheric Dispersion of Heavy Gases and Small Particles. Berlin: Springer Verlag; 1984:129-138.

[89] McQuaid J. Observations on the current status of field experimentation on heavy gas dispersion. In: Ooms G, Tennekes H, editors. Atmospheric Dispersion of Heavy Gas and Small Particles. Berlin: Springer Verlag; 1983:241-265.

[90] McQuaid J. J Hazard Mater. 1987;16:1-8. DOI: 10.1016/0304-3894(87)80024-9.

[91] Davies ME, Singh S. J Hazard Mater. 1985;11/3:91.

[92] Nielsen M, Bengtsson R, Jones C, Nyren K, Ott S, Ride D. Design of the FLADIS field experiments with dispersion of liquefied ammonia. Riso Report R 755. Roskilde, Denmark: Riso National Laboratory; 1994. 
[93] Nielsen M. Surface concentrations in the FLADIS field experiments. Riso Report R 995. Roskilde, Denmark; Riso National Laboratory; 1996.

[94] Nielsen M, Ott S, Jorgensen HE, Bengtsson R, Nyren K, Winter S, et al. J Hazard Mater. 1997;56:59-105. PII S0304-3894(97)00029-0.

[95] Nielsen M, Ott S. J Hazard Mater. 1999;A67:41-58. PII S0304-3894(99)00016-3.

[96] Heinrich M, Scherwinski R. Research on propane releases under realistic conditions. Determination of gas concentrations considering obstacles, TUV Report 123U1000780. Germany: Technischer Uberwachungs Verain; 1990

[97] Schatzmann M, Marotzke K, Donat J. A research on continuous and instantaneous heavy gas clouds. Contribution to project EV 4T-0021-D to the final report of the joint CEC project. Hamburg, Germany: University of Hamburg; 1991.

[98] Schatzmann M, Snyder WH, Lawson RE. Atmos Environ. 1993;27:1105-1116. DOI: 10.1016/0960-1686(93)90145-0.

[99] Donat J, Schatzmann M. J Wind Eng Ind Aerodyn. 1999;83:361-370. DOI: http://dx.doi.org/10.1016/S0167-6105(99)00085-9.

[100] Builtjes PH. Research on continuous and instantaneous heavy gas releases TNO-ME Report 92-135. Appeldorn, The Netherlands: TNO; 1992

[101] Van Oort H, Builtjes PJH. Research on continuous and instantaneous heavy gas clouds. MT-TNO wind tunnel experiments, TNO report 91-026. Apeldoorn, The Netherlands: TNO Division of Technology for Society; 1991.

[102] Duijm NJ. Research on the dispersion of two phase flashing releases - FLADIS. Fladis final report $\mathrm{R}$ 94-451. Apeldorn, The Netherlands: TNO; 1994.

[103] Hall DJ, Waters RA, Marsland A, Upton SL. Repeat variability in instantaneous released heavy gas clouds dispersing over fences. Some wind tunnel model experiments. Stevenage, Herdfordshire, UK: Warren Spring Laboratories; 1991.

[104] Davies JKW, Hall DJ. J Hazard Mater. 1996;49:311-328. DOI: http://dx.doi.org/10.16/03043894(96)01748-7.

[105] Hall RC, editor. Evaluation of modelling uncertainty (EMU). CFD modelling of near field atmospheric dispersion. EU Project EV5V-CT94-0531, Final Report. Epsom, Surrey, UK: WS Atkins Consultants Limited; 1997.

[106] Havens J, Spicer T. Proc Saf Prog. 2005;24:181-186. DOI: 10.1002/prs.10080.

[107] Hanna SR, Steinberg KW. Atmos Environ. 2001;35:2223-2229. PII S1352-2310(00)00284-3.

[108] Briggs GA, Britter RE, Hanna SR, Havens JA, Robins AG, Snyder WH. Atmos Environ. 2001;35:2265-2284. PII S1352-2310(00)00360-5.

[109] Britter RE, Briggs GA, Hanna SR, Robins AG. Atmos Environ. 2003;37:3885-3894. DOI: 10.1016/S1352-2310(03)00299-1.

[110] Hanna SR, Chang JC. Atmos Environ. 2001;35:2231-2242. PII S1352-2310(00)00481-7.

[111] Havens J, Walker H, Spicer TO. Atmos Environ. 2001;35:2305-2317. PII S1352-2310(00)00491-x.

[112] Robins A, Castro I, Hayden P, Steggel N, Contini D, Heist D, et al. Atmos Environ. 2001;35:2253-2263. PII S1352-2310(01)00073-5.

[113] Robins A, Castro I, Hayden P, Steggel N, Contini D, Heist D, et al. Atmos Environ. 2001;35:2243-2252. PII S1352-2310(01)00072-3.

[114] Snyder WH. Atmos Environ. 2001; 35:2285-2304. PII S1352-2310(00)00214-4.

[115] Hanna S, Britter R, Argenta E, Chang J. J Hazard Mater. 2012;213-214:405-412. DOI: 10.1016/j.jhazmat.2012.02.013.

[116] Wannberg VE, Williams G, Sawayer P, Venedam R. J Appl Metoeor Climatol. 2010;49:1805-1817. DOI: http://dx.doi.org/10.1175/2010JAMC2383.1. 


\title{
PRZEGLĄD MODELI DYSPERSJI W ATMOSFERZE GAZÓW CIĘŻSZYCH OD POWIETRZA. CZĘŚĆ II. OCENA JAKOŚCI MODELI
}

Katedra Ochrony Środowiska, Wydział Inżynierii Środowiska, Politechnika Warszawska

\begin{abstract}
Abstrakt: Publikacja ta stanowi drugą część dwuczęściowego artykułu. W pierwszej części dokonano klasyfikacji matematycznych modeli rozprzestrzeniania się w atmosferze gazów cięższych od powietrza i scharakteryzowano wyróżnione grupy. W tej części przedstawiono procedury oceny jakości modeli, podsumowano główne wyniki projektów, w których oceniano modele, i opisano bazy danych związane z zagadnieniem rozprzestrzeniania się gazów cięższych od powietrza. Jakość modeli ma bardzo duże znaczenie, jako że na podstawie wyników modelowania podejmowane są decyzje dotyczące bezpieczeństwa ludzi i środowiska. Uwagę zwrócono na działania podejmowane w krajach Unii Europejskiej i Stanach Zjednoczonych Ameryki. Obejmuje to prace prowadzone przez grupy naukowców nazwane MEG, HGDEG, projekty znane pod nazwami REDIPHEM, SMEDIS, DATABASE i prace nad oceną jakości modeli w Sigma Research Corporation.
\end{abstract}

Słowa kluczowe: ocena jakości modeli, modele matematyczne, gazy cięższe od powietrza, dyspersja atmosferyczna 